\title{
The role of palliative radiation therapy in treating pleural or peritoneal disseminated tumors: 22 cases and a review of the literature
}

\author{
Naoya Ishibashi ${ }^{1}$, Toshiya Maebayashi ${ }^{1}$, Masaharu Hata ${ }^{2}$, Masahiro Okada ${ }^{1}$ \\ ${ }^{1}$ Department of Radiology, Nihon University School of Medicine, Itabashi-ku, Tokyo, Japan; ${ }^{2}$ Department of Radiation Oncology, Yokohama City \\ University Graduate School of Medicine, Yokohama-shi, Kanagawa, Japan \\ Contributions: (I) Conception and design: All authors; (II) Administrative support: None; (III) Provision of study materials or patients: N Ishibashi; \\ (IV) Collection and assembly of data: N Ishibashi; (V) Data analysis and interpretation: N Ishibashi; (VI) Manuscript writing: All authors; (VII) Final \\ approval of manuscript: All authors. \\ Correspondence to: Naoya Ishibashi. Department of Radiology, Nihon University School of Medicine, 30-1 Oyaguchi Kami-cho, Itabashi-ku, Tokyo \\ 173-8610, Japan. Email: ishibashi.naoya@nihon-u.ac.jp.
}

Background: Local radiation therapy (RT) can provide pain relief and reduce bleeding resulting from pleural or peritoneal dissemination of primary tumors. However, the optimal RT exposure dose for such tumors is unclear and the response rate is unknown. In this study, we examined the effectiveness of palliative RT for pleural or peritoneal disseminated tumors to determine the optimal dose in these patients.

Methods: The data of 22 patients with pleural- or peritoneal-disseminated tumors who were treated with local RT at our institution between 2011 and 2019 were retrospectively reviewed.

Results: Among these patients, 9 (40.9\%) had pleural tumors, 13 (59.1\%) had peritoneal tumors and 2 had tumors in the peritoneum and umbilicus. The most common primary tumors were lung $(22.8 \%)$ and pancreatic cancer (18.2\%). RT was mainly administered for pain alleviation (72.7\%). Three patients (13.6\%) received RT for hemostasis. Thirteen patients (59.1\%) received a regimen of $30 \mathrm{~Gy} / 10$ fractions (fr), with the total dosage for all patients ranging from 27 to 56 Gy. No grade 2 or higher RT-related adverse events occurred. Three and four patients obtained complete and partial responses, respectively. The timing of the measurement of response to pain relief ranged from 0 to 232 (median, 21) days upon completion of RT. Overall response to pain relief occurred in nine of 16 patients $(56.3 \%)$ with pain before RT. Hemostasis was confirmed in 2 of the 3 patients $(66.7 \%)$ with bleeding before RT. Twelve of 20 (60\%) patients with symptoms before RT responded to RT. Disease-specific survival (DSS) time after RT ranged from 1 to 656 (median, 106) days.

Conclusions: Prompt palliative administration of RT to patients with advanced disease to alleviate pain from disseminated tumors may achieve therapeutic efficacy.

Keywords: Radiation therapy (RT); pleural dissemination; peritoneal dissemination

Submitted Nov 13, 2019. Accepted for publication Aug 04, 2020.

doi: $10.21037 /$ apm-19-495

View this article at: http://dx.doi.org/10.21037/apm-19-495 


\section{Introduction}

Pleural or peritoneal dissemination from malignant tumors can occasionally induce tumorigenesis, and the resultant tumors may invade the surrounding tissues and cause pain or bleeding. If such tumors are identified by imaging approaches such as computed tomography, local radiation therapy (RT) may be selected to alleviate symptoms. However, few reports have focused on the effects of palliative RT or the optimal irradiation dose for pleural or peritoneal disseminated tumors. We assessed the significance of RT by investigating the purpose, effect, and dose of RT in patients who received palliative RT for pleural or peritoneal disseminated tumors arising from malignant tumors at our hospital between 2011 and 2019. We present the following article in accordance with the STROBE reporting checklist (available at http://dx.doi. org/10.21037/apm-19-495).

\section{Methods}

We retrospectively reviewed the data of 22 patients with pleural or peritoneal disseminated tumors treated with local RT between 2011 and 2019. The Kaplan-Meier method was used to determine the probability of disease-specific survival (DSS) from the date of completion of RT. This study was approved by our institutional review board of Nihon University Itabashi Hospital (Ref No. RK-1910088). Informed consent was obtained from all patients and the study was performed in accordance with the Declaration of Helsinki (as revised in 2013).

\section{Results}

The clinical data of all 22 patients are summarized in Table 1. Thirteen patients (59.1\%) were men and 9 (40.9\%) were women. The age at initiation of RT ranged from 47 to 80 (median, 67) years.

Regarding the irradiated disseminated tumor location, tumors in the pleura occurred in 9 (40.9\%) patients, peritoneum in $13(59.1 \%)$ and 2 tumor occurred in peritoneum and umbilicus. Regarding the primary tumor, the most common tumor type was lung cancer, which was identified in 5 patients $(22.8 \%)$ and all were irradiated for pleural disseminated tumors. Pancreatic cancer was the second most common cancer type and was diagnosed in 4 patients $(18.2 \%)$. Two patients were irradiated for peritoneum and umbilical tumors.
Concurrent metastasis of irradiated disseminated tumors at RT was observed in all but three patients. The most common purpose of RT was pain relief in 16 patients (72.7\%). The second most common purpose was hemostasis in three patients (13.6\%); specifically, RT was administered to stop direct bleeding from tumors in two patients and to treat hematuria due to bleeding from a tumor invading the bladder in one patient (1). The two patients without concurrent metastasis with irradiated disseminated tumors at RT were asymptomatic and were treated with RT for local control. Figure 1 shows RT dosimetry for peritoneum and abdominal wall disseminated tumors from pancreatic cancer with refractory pain. The most common RT regimen was $30 \mathrm{~Gy} / 10$ fractions (fr) in 13 patients (59.1\%), and the total RT dose ranged widely, from 27 to 56 Gy. No grade 2 or higher RT-related toxicities (National Cancer Institute Common Terminology Criteria for Adverse Events 4.03) (2) were observed. The categories of bone metastases (3) were used to substitute for the categories of pain relief. Based on scores on a $0-10$ numerical rating scale and the extent of analgesic use, complete and partial responses were achieved in four and four patients, respectively. Indeterminate responses were obtained in one patient. The timing of the measurement of response to pain relief ranged from 0 to 232 days with a median time of 21 days after RT completion. Overall response to pain relief was observed in 9 of 16 patients $(56.3 \%)$ with pain before RT. Hemostasis or reduced bleeding was confirmed in 2 of 3 patients $(66.7 \%)$ with bleeding before RT. In one patient with pre-existing superior vena cava (SVC) syndrome before RT, SVC syndrome resolved. Of 20 patients who had some symptoms before RT, 12 patients (60\%) responded to RT. Survival time after RT completion ranged from 1 to 656 days with a median of 106 days (Figure 2).

\section{Discussion}

RT is widely known to have a role in preventing dissemination; hemithorax RT is administered after surgery for malignant mesothelioma and whole abdominal RT after surgery for ovarian cancer (4-7). However, local RT for pleural or peritoneal disseminated tumors has been described in only a few case reports. There have been no reports, to date, on its effects and the optimal radiation dose. Our literature search identified nine case reports of RT for peritoneal disseminated tumors. In five of these, RT was administered for pain relief, hemostasis, or symptom 
Table 1 Characteristics of patients treated with irradiation for pleural or peritoneal disseminated tumors and their clinical responses

\begin{tabular}{|c|c|}
\hline Characteristics & $N(\%)(n=22)$ \\
\hline Age at the time of RT, median years [range] & $67[47-80]$ \\
\hline \multicolumn{2}{|l|}{ Gender } \\
\hline Male & $13(59.1)$ \\
\hline Female & 9 (40.9) \\
\hline \multicolumn{2}{|l|}{ Disseminated tumor location } \\
\hline Pleura & 9 (40.9) \\
\hline Peritoneum & $13(59.1)$ \\
\hline \multicolumn{2}{|l|}{ Primary tumor site } \\
\hline Larynx & $1(4.5)$ \\
\hline Thyroid & $1(4.5)$ \\
\hline Lung & $5(22.8)$ \\
\hline Thymoma & $1(4.5)$ \\
\hline Stomach & $1(4.5)$ \\
\hline Pancreas & $4(18.2)$ \\
\hline Gallbladder & $1(4.5)$ \\
\hline Bile duct & $1(4.5)$ \\
\hline Jejunum & $1(4.5)$ \\
\hline Appendix & $1(4.5)$ \\
\hline Colon & $2(9.1)$ \\
\hline Ovary & $2(9.1)$ \\
\hline Uterine body & $1(4.5)$ \\
\hline \multicolumn{2}{|l|}{ Concurrent metastasis at RT } \\
\hline Yes & $19(86.4)$ \\
\hline No & $3(13.6)$ \\
\hline \multicolumn{2}{|l|}{ Purpose of RT } \\
\hline Pain relief & $16(72.7)$ \\
\hline Hemostasis & $3(13.6)$ \\
\hline SVC syndrome release & $1(4.5)$ \\
\hline No symptom & $2(9.1)$ \\
\hline \multicolumn{2}{|l|}{$\mathrm{RT}$ regimen (dose/fractions) } \\
\hline $56 \mathrm{~Gy} / 28 \mathrm{fr}$ & $1(4.5)$ \\
\hline $50.4 \mathrm{~Gy} / 28 \mathrm{fr}$ & $1(4.5)$ \\
\hline $45 \mathrm{~Gy} / 15 \mathrm{fr}$ & $1(4.5)$ \\
\hline
\end{tabular}

Table 1 (continued)
Table 1 (continued)

\begin{tabular}{ll}
\hline Characteristics & $N(\%)(\mathrm{n}=22)$ \\
\hline $45 \mathrm{~Gy} / 25 \mathrm{fr}$ & $1(4.5)$ \\
$39 \mathrm{~Gy} / 13 \mathrm{fr}$ & $1(4.5)$ \\
$38 \mathrm{~Gy} / 19 \mathrm{fr}$ & $1(4.5)$ \\
$36 \mathrm{~Gy} / 12 \mathrm{fr}$ & $1(4.5)$ \\
$30 \mathrm{~Gy} / 10 \mathrm{fr}$ & $13(59.1)$ \\
$28 \mathrm{~Gy} / 7 \mathrm{fr}$ & $1(4.5)$ \\
$27 \mathrm{~Gy} / 9 \mathrm{fr}$ & $1(4.5)$ \\
Response & \\
Yes & $12(60.0)$ \\
No & $8(40.0)$ \\
Survival time after RT, median days [range] & $106[1-656]$ \\
\hline *, response rate in 20 cases with symptoms. RT, radiation \\
therapy; SVC, superior vena cava.
\end{tabular}

alleviation (Table 2). We also previously reported a case in which hemostasis was achieved with hemostatic-intent RT for hematuria caused by a peritoneal disseminated tumor invading the bladder (1). In all five reported cases, symptoms were successfully alleviated; however, the actual response rate to RT for symptom alleviation is unknown. The RT regimens described in the case reports widely ranged from $20 \mathrm{~Gy} / 5$ fr to $50 \mathrm{~Gy} / 25 \mathrm{fr}$. The irradiation doses tended to be higher in patients without concurrent metastasis with irradiated disseminated tumors at RT. Meanwhile, no reports were identified concerning RT administration to alleviate symptoms associated with pleural disseminated tumors. Regarding RT for symptom alleviation, the role of RT in relieving pain due to bone metastasis has been established. For example, meta-analyses have shown an overall pain response rate of RT ranging from $58.7 \%$ to $62.1 \%$ and a complete pain response rate ranging from $23 \%$ to $34 \%$ (16-18). In our present study, the overall pain response was observed in $56.3 \%$ of patients with pain, with our therapeutic effect being slightly inferior to that for pain due to bone metastasis. This may be explained by the difference in the timing of the measurement of response rates. Previous studies involving patients with bone metastasis measured patients' response rates at 3-6 weeks after RT completion (19-21). However, the response rate in our patients with pain was measured at a median of 21 days 


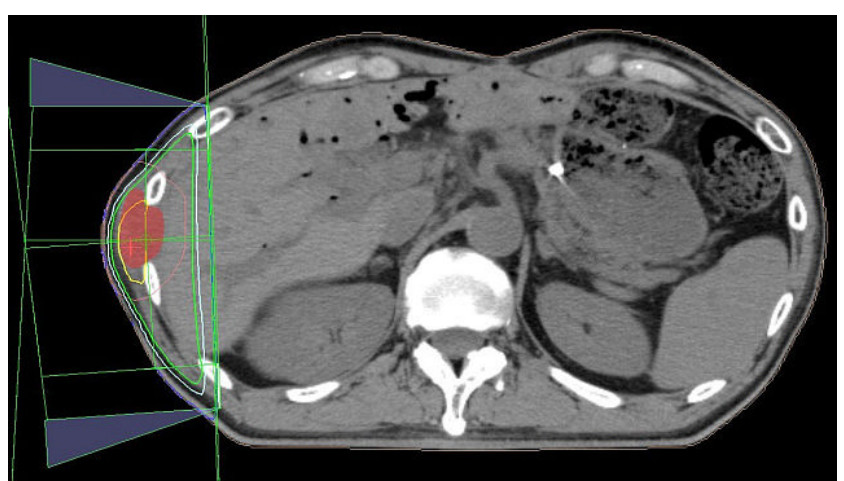

Figure 1 Computed tomography scan with RT dosimetry for a peritoneum disseminated tumor from pancreatic cancer. The gross tumor volume (red color fill) and clinical target volume (light red line) was well covered by the prescribed isodose: $100 \%$ isodose line is yellow, $95 \%$ is green, $90 \%$ is light cyan, and $50 \%$ is blue. RT, radiation therapy.

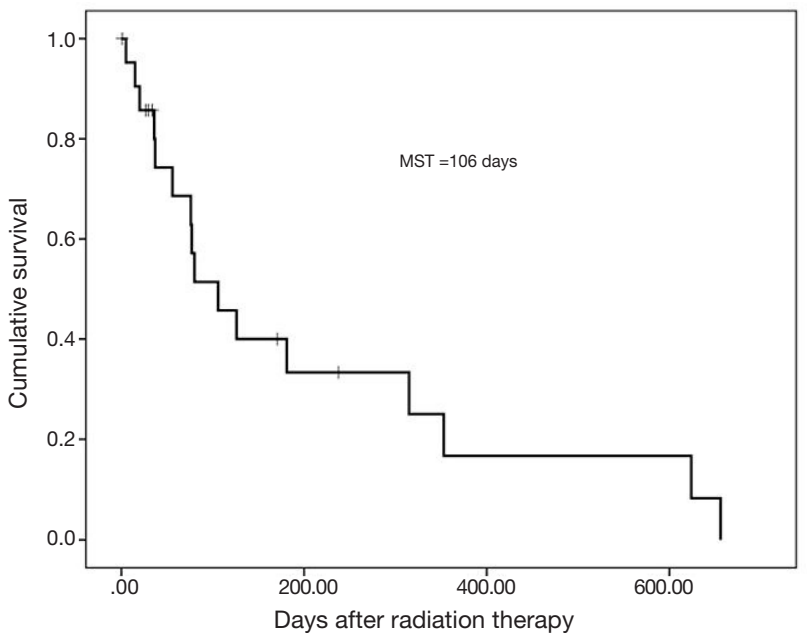

Figure 2 Kaplan-Meier DSS curves. The MST after RT completion was 106 days. DSS, disease-specific survival; MST, median survival time; RT, radiation therapy.

Table 2 Reported cases of peritoneal disseminated tumors treated with RT

\begin{tabular}{|c|c|c|c|c|c|c|c|c|c|}
\hline Patient & $\begin{array}{l}\text { Age }^{\star} \\
\text { (years) }\end{array}$ & Gender & $\begin{array}{l}\text { Disseminated } \\
\text { tumor location }\end{array}$ & $\begin{array}{l}\text { Primary tumor } \\
\text { site }\end{array}$ & $\begin{array}{c}\text { Concurrent } \\
\text { metastasis at RT }\end{array}$ & Purpose of RT & $\begin{array}{l}\text { RT regimen (dose/ } \\
\text { fractions) }\end{array}$ & Response & Reference \\
\hline 1 & 64 & Male & Peritoneum & Stomach & Yes & Hemostasis & $30 \mathrm{~Gy} / 10 \mathrm{fr}$ & Yes & (1) \\
\hline 3 & 49 & Male & Abdominal wall & Pancreas & Yes & Pain relief & $\begin{array}{c}40 \text { Gy (total dose } \\
\text { only) }\end{array}$ & Yes & (9) \\
\hline 5 & 82 & Male & Peritoneum & Stomach & No & $\begin{array}{l}\text { Dyschezia } \\
\text { release }\end{array}$ & $40 \mathrm{~Gy} / 20 \mathrm{fr}$ & Yes & (11) \\
\hline 6 & 79 & Male & Abdominal wall & Bile duct & Yes & No symptom & $30 \mathrm{~Gy} / 10 \mathrm{fr}$ & $\begin{array}{c}\text { Not } \\
\text { mentioned }\end{array}$ & (12) \\
\hline
\end{tabular}

*, age at first visit and not at RT. RT, radiation therapy.

after RT completion. However, as the survival time after RT completion was short, pain response in five patients was measured at 0 or 1 day after RT completion. It seems that if RT is administered in the early stages to alleviate pain due to disseminated tumors, patients may survive until therapeutic efficacy can be attained.

In our present study, $30 \mathrm{~Gy} / 10 \mathrm{fr}$, a RT regimen commonly used for bone metastasis, was delivered, but the median survival time (MST) after RT completion was as short as 106 days. Although short-term irradiation such as RT of 8 Gy in a single fraction for bone metastasis could also be considered, attention should be paid to RT doses that would be delivered to the surrounding gastrointestinal tract in cases with peritoneal disseminated tumors. 
Regarding the association between disseminated tumors and prognosis, the survival time after umbilical metastasis from various primary tumor sites, which is conventionally known as Sister Mary Joseph's nodule, reportedly range from 1 week to 36 months, and the MST after umbilical metastasis from ovarian or uterine tube carcinoma is 26 months $(22,23)$. Furthermore, a literature review of cutaneous metastases from pancreatic cancer, including umbilical metastasis, indicated that the survival time after cutaneous metastasis ranged from a few days to 19 months with a MST of 5 months (24). In this review, the survival time was significantly more improved in patients receiving any therapy including RT than in those receiving no therapy. In the current study, the MST after RT completion was 106 days. The association between RT and prognosis of disseminated tumors may differ depending on the primary tumor site or concurrent metastasis at RT. We will perform further studies to investigate the significance of RT for disseminated tumors from malignant tumors in terms of survival time by comparing patients receiving RT with those receiving no therapy.

\section{Conclusions}

Our findings indicate that if RT is administered in the early stages of cancer to alleviate pain due to disseminated tumors, patients may survive until therapeutic efficacy can be attained.

\section{Acknowledgments}

We thank H. Nikki March, PhD, from Edanz Group (www. edanzediting.com/ac) for editing a draft of this manuscript and helping to draft the abstract.

Funding: None.

\section{Footnote}

Reporting Checklist: The authors have completed the STROBE reporting checklist. Available at http://dx.doi. org/10.21037/apm-19-495

Data Sharing Statement: Available at http://dx.doi. org/10.21037/apm-19-495

Conflicts of Interest: All authors have completed the ICMJE uniform disclosure form (available at http://dx.doi. org/10.21037/apm-19-495). The authors have no conflicts of interest to declare.

Ethical Statement: The authors are accountable for all aspects of the work in ensuring that questions related to the accuracy or integrity of any part of the work are appropriately investigated and resolved. This study was approved by our institutional review board of Nihon University Itabashi Hospital (Ref No. RK-191008-8). Informed consent was obtained from all patients and the study was performed in accordance with the Declaration of Helsinki (as revised in 2013).

Open Access Statement: This is an Open Access article distributed in accordance with the Creative Commons Attribution-NonCommercial-NoDerivs 4.0 International License (CC BY-NC-ND 4.0), which permits the noncommercial replication and distribution of the article with the strict proviso that no changes or edits are made and the original work is properly cited (including links to both the formal publication through the relevant DOI and the license). See: https://creativecommons.org/licenses/by-nc-nd/4.0/.

\section{References}

1. Ishibashi N, Maebayashi T, Aizawa T, et al. Refractory haematuria resulting from peritoneal dissemination of metastatic gastric cancer: radiation therapy for a nodule infiltrating the urinary bladder. Urol J 2017;14:2982-4.

2. National Cancer Institute Common Terminology Criteria for Adverse Events (CTCAE) 4.03. Jun 14, 2010.

3. Chow E, Hoskin P, Mitera G, et al. Update of the international consensus on palliative radiotherapy endpoints for future clinical trials in bone metastases. Int $\mathbf{J}$ Radiat Oncol Biol Phys 2012;82:1730-7.

4. Gordon W Jr, Antman KH, Greenberger JS, et al. Radiation therapy in the management of patients with mesothelioma. Int J Radiat Oncol Biol Phys 1982;8:19-25.

5. Yajnik S, Rosenzweig KE, Mychalczak B, et al. Hemithoracic radiation after extrapleural pneumonectomy for malignant pleural mesothelioma. Int J Radiat Oncol Biol Phys 2003;56:1319-26.

6. Dembo AJ. Abdominopelvic radiotherapy in ovarian cancer. A 10-year experience. Cancer 1985;55:2285-90.

7. Dembo AJ. Epithelial ovarian cancer: the role of radiotherapy. Int J Radiat Oncol Biol Phys $1992 ; 22: 835-45$.

8. Takahashi H, Konishi M, Nakagohri T, et al. Aggressive multimodal treatment for peritoneal dissemination and 
needle tract implantation of hepatocellular carcinoma: a case report. Jpn J Clin Oncol 2004;34:551-5.

9. Koga C, Tanemura M, Wada H, et al. A case report of port-site metastasis of pancreatic cancer after laparoscope assistted distal pancreatectomy. Gan To Kagaku Ryoho 2011;38:2454-6.

10. Kabashima A, Kudo K, Nakamura T, et al. A case of longterm survival following combined modality therapy for peritoneal disseminated recurrence of duodenal cancer. Gan To Kagaku Ryoho 2012;39:1969-71.

11. Shirai J, Cho H, Fujikawa H, et al. A case of rectal stenosis due to peritoneal dissemination from gastric cancer that was treated with chemoradiation therapy. Gan To Kagaku Ryoho 2013;40:2268-70.

12. Sudo N, Soma D, Hirose Y, et al. A case of distal bile duct carcinoma with PTBD catheter tract metastasis followed by abdominal wall recurrence. Tando 2015;29:247-53.

13. Kumaran PD, Sharma DN, Jayanthi C, et al. Adenocarcinoma cervix with umbilical metastasis. Natl Med J India 2016;29:174-5.

14. Udagawa M, Mizuno Y, Ohnishi I, et al. A case report of gastric cancer with positive peritoneal lavage cytology and metachronous Schnitzler's metastasis treated with multimodality therapy. Gan To Kagaku Ryoho 2017;44:1626-8.

15. Takizawa K, Sakata J, Ando T, et al. A case of peritoneal recurrence of invasive ductal carcinoma derived from intraductal papillary mucinous neoplasm after surgery treated with palliative radiation therapy and chemotherapy. Gan To Kagaku Ryoho 2019;46:372-4.

16. Sze WM, Shelley MD, Held I, et al. Palliation of metastatic bone pain: single fraction versus multifraction

Cite this article as: Ishibashi N, Maebayashi T, Hata M, Okada $M$. The role of palliative radiation therapy in treating pleural or peritoneal disseminated tumors: 22 cases and a review of the literature. Ann Palliat Med 2020;9(5):2586-2591. doi: 10.21037/apm-19-495 radiotherapy--a systematic review of randomised trials. Clin Oncol (R Coll Radiol) 2003;15:345-52.

17. Wu JS, Wong R, Johnston M, et al. Meta-analysis of dose-fractionation radiotherapy trials for the palliation of painful bone metastases. Int J Radiat Oncol Biol Phys 2003;55:594-605.

18. Chow E, Zeng L, Salvo N, et al. Update on the systematic review of palliative radiotherapy trials for bone metastases. Clin Oncol (R Coll Radiol) 2012;24:112-24.

19. Foro Arnalot P, Fontanals AV, Galcerán JC, et al. Randomized clinical trial with two palliative radiotherapy regimens in painful bone metastases: 30 Gy in 10 fractions compared with $8 \mathrm{~Gy}$ in single fraction. Radiother Oncol 2008;89:150-5.

20. Amouzegar-Hashemi F, Behrouzi H, Kazemian A, et al. Single versus multiple fractions of palliative radiotherapy for bone metastases: a randomized clinical trial in Iranian patients. Curr Oncol 2008;15:151.

21. Safwat E, El-Nahas T, Metwally H, et al. Palliative fractionated radiotherapy for bone metastases clinical and biological assessment of single versus multiple fractions. J Egypt Natl Canc Inst 2007;19:21-7.

22. Powell FC, Cooper AJ, Massa MC, et al. Sister Mary Joseph's nodule: a clinical and histologic study. J Am Acad Dermatol 1984;10:610-5.

23. Otsuka I, Matsuura T. Skin metastases in epithelial ovarian and fallopian tube carcinoma. Medicine (Baltimore) 2017;96:e7798.

24. Zhou HY, Wang XB, Gao F, et al. Cutaneous metastasis from pancreatic cancer: a case report and systematic review of the literature. Oncol Lett 2014;8:2654-60. 